\title{
MicroRNA775 targets a $\beta$-(1,3)-galactosyltransferase to regulate growth and development in Arabidopsis thaliana
}

Parneeta Mishra ${ }^{1,2}$, Akanksha Singh ${ }^{1,2}$, Ashwani Kumar Verma ${ }^{1,2}$, Rajneesh Singh ${ }^{1}$, Sribash $\operatorname{Roy}^{1,2 *}$

\section{Affiliations:}

1. Molecular Biology and Biotechnology Division, CSIR-National Botanical Research Institute, Lucknow, 226001, India.

2. Academy of Scientific and Innovative Research (AcSIR), Ghaziabad, 201002, India.

* Corresponding Author: Sribash Roy

Email: sribashroy@nbri.res.in 


\section{Highlights}

- The role of an uncharacterized microRNA, miR775 has been explored

- miR775 targets a probable $\beta-(1,3)$-galactosyltransferase involved in complex carbohydrate biosynthesis

- miR775 regulates rosette size in A. thaliana and may play role under UV light and hypoxia

\section{Abstract}

MicroRNAs are critical regulators of gene expression in plants and other organisms, and are involved in regulating plethora of developmental processes. Evolutionarily, miRNAs can be ancient and conserved across species or recently evolved and young, which are not conserved across diverse plant groups. miR775 is a non-conserved miRNA identified only in Arabidopsis thaliana. Here, we investigated the functional significance of miR775 in A. thaliana and observed that miR775 targets a probable $\beta$-(1,3)-galactosyltransferase gene at post transcriptional level. Phenotypic analysis of miR775 over-expression lines and the target mutant suggested miR775 regulates rosette size by elongating petiole length and increasing leaf area. Further, the expression of miR775 was found to be up-regulated in response to UV-B and hypoxia. Our results also suggest that miR775 regulated $\beta$-(1,3)-galactosyltransferase may involve in regulating the $\beta$-(1,3)-galactan content of arabinogalactans. Collectively, our findings establish a role of miR775 in regulating growth and development in A. thaliana.

Keywords: miR775, $\beta$-(1,3)-galactosyltransferase, arabinogalactans, UV, hypoxia

\section{Introduction}

MicroRNAs (miRNAs) belong to a class of small RNA of 20-24 nucleotides in length. They are processed from stem loop like structures of primary transcript, transcribed by RNA polymerase II to mature form by the activity of DCL1 protein. After processing miRNAs are loaded onto the ARGONAUTE 1 protein. The ARGONAUTE 1 loaded miRNA constitutes the RNA induced gene silencing complex (RISC) and carries out either post-transcriptional gene silencing or translational inhibition (Reinhart et al., 2002; Bartel, 2004; Vaucheret, 2008; 
Voinnet, 2009). In the past two decades, biological relevance of numerous miRNA in plants has been deciphered by observing the effect of miRNA over-expression or null expression, and also by portrayal of the target genes (Wang et al., 2005; Koyama et al., 2010; Marin et al., 2010; Zhao et al., 2015; Chung et al., 2016; Koyama et al., 2017). There exists plethora of information supporting the instrumental role of miRNA in plant stress response (Sunkar and Zhu, 2004; Lv et al., 2010; Zhou et al., 2010; Eckardt, 2012), growth and development (Wu and Poethig, 2006; Wu et al., 2006; Nag et al., 2009; Koyama et al., 2010; Marin et al., 2010; Rodriguez et al., 2010), signal transduction (Achard et al., 2004; Guo et al., 2005; Mallory et al., 2005), nutrient homeostasis (Chiou et al., 2006; Liang et al., 2010; Kawashima et al., 2011) and in regulating their own biogenesis (Xie et al., 2003; Vaucheret et al., 2004). However, majority of studies are focused on ancient miRNAs that are conserved across diverse plant species.

Despite the fact that miRNAs are well conserved between diverged plants, the vast repertoire of miRNA in plants is largely composed of non-conserved miRNAs. According to the reports, most of the non-conserved miRNAs are either restricted to a particular lineage or species. This gives an impression that a significant proportion of miRNA genes are young that have evolved much later in the evolutionary past. In disparity with the conserved miRNAs that largely target transcriptional regulators, the non-conserved miRNA are reported to target wide range of genes involved in varied plant processes (Rajagopalan et al., 2006; Fahlgren et al., 2007; Cuperus et al., 2011). For example, miR163 that is only reported in Arabidopsis has been identified to target members of a methyltransferase family, while miR158 which is confined only to the family Brassicaceae is known to target genes expressing PPR proteins (Chung et al., 2016; Ma et al., 2017). miR857 that is only encoded in Arabidopsis has been found to influence the growth of vascular tissue by targeting Laccase 7 (Zhao et al., 2015). Besides targeting protein coding genes, some non-conserved 22 nt-miRNAs, for example miR173 targets non-coding RNA, triggering phasi RNA generation in A. thaliana and A. lyrata (Montgomery et al., 2008; Felippes and Weigel, 2009; Chen et al., 2010; Cuperus et al., 2010). Thus newly evolved miRNAs can have a considerable impact in managing the intricate processes in the plant body. Nevertheless, there exists discrepancy over the functional involvement of young miRNAs into the plant regulatory network. Studies suggest that it is not necessary that all the newly identified miRNAs have gained a function. Some may be in the evolutionary transient phase and disappear 
during the course of evolution (Rajagopalan et al., 2006; Fahlgren et al., 2007; Cuperus et al., 2011). Thus the function of newly evolved species specific miRNAs remains largely unexplored. miR775 is one such young uncharacterized miRNA reported so far only from A. thaliana (Lu et al., 2006; Rajagopalan et al., 2006). The precursor of this miRNA maps on chromosome 1 and is 123 nucleotides (nts) long that is processed into its 20-nts long mature form. In our previous study, we observed that the expression of miR775 was higher in the high altitude populations of $A$. thaliana (Chit and Mun) as compared to the lower altitude population (Deh) under both native and control conditions (Tripathi et al., 2019) (Supplementary Table S4). Thus, we speculated that miR775 might have a significant role in A. thaliana. We show that miR775 targets a probable $\beta$-(1,3)-galactosyltransferase belonging to glycosyltransferase 31 (GT31) family of carbohydrate active enzymes that might be involved in regulating arabinogalactan and/or complex carbohydrate biosynthesis, an important component of plant cell wall. We also show increased expression of miR775 under UV light and hypoxic conditions, and thus might help plants under such abiotic stress conditions, mostly prevalent in high elevated areas. However, during our reporting time of this work Zhang et al. (2021) also reported role of miR775 in A. thaliana.

\section{Material and methods}

\subsection{Plant material}

A. thaliana ecotype, Columbia-0 (Col-0) was used for all the experimental purposes. Seeds of T-DNA insertion line for target knockout mutant (SALK_151601) and miRNA mutant (SALK_043658) were obtained from Arabidopsis Biological Resource Center (ABRC, USA). A. thaliana plants were grown at $22^{\circ} \mathrm{C}$ under controlled conditions with $140 \mu \mathrm{mol} / \mathrm{m}^{2} / \mathrm{sec}$ light intensity and 16-hours-light/8-hours-dark photoperiod cycle. Seeds were stratified for 4 days at $4^{0} \mathrm{C}$ in dark before being transferred to the controlled culture room. The SALK lines were first confirmed for homozygosity using the primer combination of LBb1.3+LP+RP as discribed in GABI (http://signal.salk.edu/tdnaprimers.2.html), and then using qRT-PCR for functional confirmation. Preliminary screening indicated that the T-DNA inserted line SALK_043658 used as probable miR775 mutant was not an effective mutant and hence was not used in further studies.

\subsection{RNA isolation and gene expression analyses by qRT-PCR}


Total RNA was isolated using mirVana ${ }^{\mathrm{TM}}$ miRNA/ total RNA isolation kit (Ambion, USA) as per manufacturer's protocol. RNA integrity was checked by resolving $2 \mu$ l of total RNA on $1 \%$ agarose gel. The RNA was subjected to DNase (Turbo DNaseI) treatment and cDNAs was synthesized from one microgram $(\mu \mathrm{g})$ of total RNA with miR775 stem loop primer using Super-Script III reverse transcriptase (Invitrogen, USA). To check the expression level of miR775, cDNAs were amplified using miR775 specific forward primer and stem loop specific universal reverse primer. For mRNA expression analysis, qRT-PCR was performed using cDNA synthesized from one $\mu$ g of total RNA with oligo-dT using First Strand cDNA synthesis kit (Invitrogen, USA) according to manufacturer's instructions and PCR amplification was done using gene specific primers.

qRT-PCR was performed using ABI SYBR Green (Applied Biosystem, USA) on ABI7300 real-time PCR system (Applied Biosystem, USA) with the following PCR conditions: denaturation at $95^{\circ} \mathrm{C}$ for 10 mins, followed by 40 cycles of denaturation at $95^{\circ} \mathrm{C}$ for $20 \mathrm{sec}$, annealing and extension together at $60^{\circ} \mathrm{C}$ for $60 \mathrm{sec}$. The expression level was determined following $2^{-\Delta \Delta \mathrm{Ct}}$ method (Schmittgen and Livak, 2008). The plant actin gene and $5 S$ rRNA gene were taken as internal control for normalization of mRNA and miRNA expression respectively. The primer sequences used are listed in Supplementary Table 1.

105

106

107

108

109

110

111

112

113

114

115

116

117 118

\subsection{In-silico target prediction and its validation}

The targets of miR775 were predicted using psRNATarget prediction tool (http://plantgrn.noble.org/psRNATarget/) at default parameters. Based on target prediction, the putative target of miR775 was validated by modified 5'RLM-RACE using First Choice RLM-RACE Kit (Ambion,USA) following manufacturer's instructions with minor modifications. Briefly, five $\mu \mathrm{g}$ of total RNA isolated from rosette tissues was subjected to adapter ligation at $37^{\circ} \mathrm{C}$ for 1 hour, followed by reverse transcription at $42^{\circ} \mathrm{C}$ for 1 hour. The prepared cDNA was used as template for outer RACE PCR using outer_adapter primer (provided by the manufacturer) and outer_GALT primer (target gene specific primer). Nested PCR was further carried out with inner_adapter primer (provided by the manufacturer) and inner_GALT primer (target gene specific primer). The PCR product was run on $2 \%$ low melting agarose gel and the PCR fragment was excised, eluted and cloned in pGEM-T easy vector (Promega, USA). Further 12 individual clones were sequenced for analysis and confirmation of the target cleavage site. 
120

121

122

123

124

125

126

127

128

129

130

131

132

133

134

135

136

137

138

139

140

141

142

\subsection{Preparation of different constructs and generation of transgenic lines}

To over-express miR775, region flanking miR775 precursor (555bp) was amplified from Col-0 genomic DNA using MIR775_PRI_forward and MIR775_PRI_reverse primers (Supplementary Table 1). The amplicon was sub cloned in pGEM-T easy vector (Promega, USA) for sequencing, and then transferred into plant expression vector pBI121 between the CAMV35S promoter and Nos terminator following digestion with $\mathrm{XbaI}$ and SacI. For promoter study, the 560 bp region upstream of the transcription start site was amplified using Q5 high fidelity DNA polymerase (NEB, England) and ligated into EcoRV digested SK+ cloning vector. The transcription start site (TSS) for MIR775 primary transcript was identified using AtmiRNET resource available online (http://atmirnet.itps.ncku.edu.tw/promoter.php.). Post sequence confirmation, the promoter region was excised from the cloning vector by sequential digestion with SmaI and XbaI, and cloned into binary vector pBI101 just upstream of the GUS reporter gene. The binary plasmid harbouring the constructs were individually transformed in Agrobacterium cells, GV3101 and plant transformation was done by floral dip method following Clough and Bent (1998). Putative transformants were first screened on MS agar plates containing kanamycin $(50 \mathrm{ug} / \mathrm{ml})$ and further by PCR.

\subsection{Phylogenetic analysis of the target gene of miR775}

Phylogenetic analysis of the target gene of miR775 was performed using online tool Phylogeny.fr. (http://www.phylogeny.fr/simple_phylogeny.cgi). Phylogeny was generated following 'one click' mode that functions on a pre-set pipeline consisting of MUSCLE for sequence alignment, G-block for alignment curation, PhyML and Tree Dyn for tree formation (Dereeper et al., 2008). Protein sequence of all the members of GT31 family in A. thaliana were retrieved from TAIR database.

\subsection{Analysis of $M I R 775$ promoter}

MIR775 promoter was analyzed by histochemical GUS staining in different tissues of MIR775PRO:GUS transgenic lines following standard method (Jefferson, 1989). Briefly, tissues were dipped in a standard solution containing $100 \mathrm{mM} \mathrm{Na-phosphate} \mathrm{buffer} \mathrm{(pH} \mathrm{7.2),} 10 \mathrm{mM}$ EDTA, $2 \mathrm{mM}$ potassium ferricyanide, $2 \mathrm{mM}$ potassium ferrocyanide and 5-bromo-4-chloro-3- 
148

149

150

151

152

153

154

155

156

157

158

159

160

161

162

163

164

165

166

167

168

169

170

171

172

173

174

175

176

177

indolyl- $\beta$-D-glucuronide at a concentration of $1 \mathrm{mg} / \mathrm{ml}$ and incubated for 16 hours at $37^{\circ} \mathrm{C}$. Stained samples were incubated in $70 \%$ ethanol for chlorophyll removal, and images were taken on Leica EZ4E stereo microscope.

The cis regulatory motifs present in the promoter sequence of MIR775 were identified using online tool Plant CARE (http://bioinformatics.psb.ugent.be/webtools/plantcare/html/).

\subsection{High light and UV-B treatment}

To examine the effect of high light intensity on expression of miR775, 21 days old plants were exposed to $600 \mu \mathrm{mole} / \mathrm{m}^{2} / \mathrm{sec}$ or $1000 \mu \mathrm{mole} / \mathrm{m}^{2} / \mathrm{sec}$ of light intensity for an hour. Leaf sample was harvested and frozen in liquid nitrogen for storage till RNA isolation. The effect of UV light on expression of miR775 was examined by exposing 21 days old plants to UV-B light (TL20W/01RS, Philips) in a close chamber maintaining a distance of $30 \mathrm{~cm}$ from the light source for an hour. Post treatment leaf tissue was collected and frozen in liquid nitrogen for storage till RNA isolation. Both high light and UV-B treatment experiments were conducted in triplicates.

\subsection{Hypoxia treatment/Mitochondrial inhibitor treatment}

Hypoxia treatment was performed by treating plants with mitochondrial inhibitors following Bond et al. (2009) with minor modifications. Briefly, the plants were sprayed with 50 $\mu \mathrm{M}$ antimycin A (AA, Sigma) and $5 \mathrm{mM}$ salicylhydroxamic acid (SHAM, Sigma) ensuring uniform spraying on all the plants. The experiment was started one hour before the onset of day light, and spraying was repeated after every hour. Sampling for RNA isolation was done three hours after treatment by pooling leaf tissue from 5 individual plants. For estimation of hydrogen peroxide, samples were collected six hours after the treatment. Hydrogen peroxide was detected by 3, 3'-diaminobenzidine (DAB) staining as described by Daudi and O'Brien (2012) and quantified following Alexieva et al. (2001). Each experiment was conducted in triplicate.

\subsection{Morphological traits analyses}

Morphological variations amongst the wild type (WT) Col-0, miRNA over-expression lines (MIR775OXP) and target mutant (SALK_151601) were recorded. Plants were grown in pots containing soilrite under standard growth conditions (as described above). Both vegetative and reproductive traits including rosette diameter (major and minor), number of leaves, leaf length and width, petiole length, bolting time, plant height, total number of siliques, silique length, and number of seeds per silique were recorded from nine to twelve individual plants of 
each WT, MIR775OXP and SALK_151601. Data were plotted as means \pm standard errors (SE). Statistical analysis was done using one way ANOVA followed by post hoc test to check the significance between the groups using R (Team, 2017).

\subsection{0. $\beta$-Galactosyl Yariv staining for detection of arabinogalactans}

$\beta$-Galactosyl Yariv ( $\beta-$ Gal-Yariv) staining in stem sections, and pollen grain was done following Popper (2011). Briefly, the stem sections were incubated in 50 $\mu 1$ of $\beta$-Gal-Yariv reagent at a concentration of $2 \mathrm{mg} / \mathrm{ml}$ in $0.15 \mathrm{M} \mathrm{NaCl}$ with continuous shaking for an hour. Post incubation washing was done with $0.15 \mathrm{M} \mathrm{NaCl}$ and samples were mounted in the same for observation under Leica DM2500 microscope.

\subsection{Calcofluor white staining for detection of seed coat phenotype}

Calcofluor white staining was performed following Willats et al. (2001). Briefly, seeds were imbibed overnight in water with continuous shaking at room temperature. Imbibed seeds were treated with $1 \mathrm{ml}$ calcofluor white solution for $10 \mathrm{mins}$, followed by repeated washing with water. Imaging was done using confocal microscope (Zeiss LSM 510) with excitations at 405 $\mathrm{nm}$.

\section{Results}

\section{1. miR775 is ubiquitously expressed in A. thaliana}

We examined the expression pattern of miR775 in different tissues of A. thaliana using qRT-PCR. Expression of miR775 was detected in all the examined tissues including seedling, root, rosette leaf, cauline leaf, stem, inflorescence and siliques. However, expression of miR775 was relatively higher in stem, siliques and inflorescence as compared to other tissues, while in roots its expression was the least (Fig. 1A). To further ascertain the expression pattern in different tissues, we cloned the putative promoter of MIR775 (560bp upstream of TSS) and fused it with GUS reporter gene. Transgenic lines expressing GUS driven by MIR775 promoter (MIR775PRO-GUS lines) were generated and analyzed by GUS staining. The GUS expression was observed in various tissues at different developmental stages (Fig.1B). GUS expression was largely confined to hypocotyls, petiole, root tips and veins of young leaves, adult rosette leaf and cauline leaf. Expression of GUS was limited to anthers and stigma of flower tissues as observed 
with higher expression of miR775 in inflorescence. Data of qRT-PCR and GUS staining indicates miR775 expresses ubiquitously in A. thaliana.

\section{2. miR775 targets a probable $\beta$-(1,3)-galactosyltransferase gene}

In-silico target prediction analysis suggested 12 putative targets of miR775 including both cleavage and translational inhibition mode of operation (Supplementary Table 2). Amongst these, the gene encoding galactosyltransferase (GALT) protein (AT1G53290.1), was likely to be the most accurate target of miR775 according to the best target identification criteria (Dai and Zhao, 2011). Earlier report also predicted it to be the target of miR775 (Fahlgren et al. 2007). Therefore, we attempted to experimentally validate this target by modified 5'RLM-RACE. Target validation using modified 5'RLM-RACE identified the gene encoding GALT protein (AT1G53290) as the only target of miR775. The maximum numbers of detected transcripts (nine of 12 clones) were cleaved at the expected position (525 nts from 5' end the mRNA) i.e. between the $10^{\text {th }}$ and $11^{\text {th }}$ nucleotide (nt) from $5^{\prime}$ end of miRNA-target pair (Fig. 2A), confirming cleavage of GALT transcript by miR775. We also attempted to validate DCL1, another predicted target of miR775 but we could not amplify the expected fragment size by PCR during modified 5'RLMRACE.

In order to gain further insight into the biological and functional significance of miR775, transgenic lines over-expressing miR775 (MIR775OXP) under the constitutively expressed CaMV35S promoter were developed and analyzed. qRT-PCR analysis of three homozygous MIR775OXP lines showed more than 100 fold higher expression of miR775 as compared to the WT (Fig. 2B). Subsequently, we determined the expression of the target GALT in different tissues of the MIR775OXP lines. qRT-PCR analyses suggested expression of target GALT was down-regulated in all the MIR775OXP lines as compared to the WT, in all the examined tissues (Fig. 2C). As expected, the OXP line having less expression of miR775 exhibited minimum target down-regulation. Further, to rule out that DCL1 was not a true target of miR775, we analysed its expression and did not observe significant down-regulation in any of the MIR775OXP line with respect to WT (Supplementary Fig. 1). We also checked the expression pattern of the target GALT in different tissues in WT. Expression of target GALT though was found to be ubiquitous, but its expression was comparatively higher in stem, inflorescence and siliques than other tissues as observed with miR775 (Supplementary Fig. 2). The high level 
expression of both miRNA and the target gene in the same tissue have been reported earlier in other miRNAs as well (Zhang and Li, 2013; Sharma et al., 2016).

The target GALT is reported to be a GT31 family member of carbohydrate-activeenzymes (http://www.cazy.org) (Strasser et al., 2007; Qu et al., 2008). Moreover, recently a few galactosytransferases have been characterized. We re-examined the phylogenetic relationship of the miR775 target GALT with other similar protein sequences. A simple protein BLAST with target GALT at NCBI identified a number of proteins with sequence similarity ranging from 72 to 100 percent and query coverage of 98 to 100 percent. Phylogenetic analysis of these proteins (98) revealed that the target GALT of miR775 was closely related to $\beta$-(1,3)galactosyltransferases of Camelina sativa and Arabidopsis lyrata (Fig. 3A). Phylogenetic analyses with 33 A. thaliana GT31 members placed it near the clade containing two $\beta$ - $(1,3)$ galactosyltransferases (AT1G87100 and AT1G33430) and one $\beta$-(1,6)-galactosyltransferase (AT1G32930), those are reported to be involved in arabinogalactan biosynthesis (Qu et al., 2008; Geshi et al., 2013; Suzuki et al., 2017) (Fig. 3B), although other members of the clade are yet to be characterized.

\section{3. miR775 is UV-B and hypoxia responsive}

Since the expression of miR775 was higher in high altitude populations, we hypothesized that the expression of miR775 might be governed by environmental factors like high light, UV light etc. prevalent in those areas. In-silico analysis of MIR775 promoter revealed the presence of several regulatory motifs including light, hypoxia etc. (Supplementary Table 3, Fig. 4A). Three types of light responsive motifs were detected, namely the ACE (CTAACGTATT) element, Box 4 (ATTAAT) and I box (cCATATCCAAT). The ACE element is reported to facilitate HY5 mediated transcriptional regulation of genes in response to light and UV-B radiation (Logemann and Hahlbrock, 2002; Safrany et al., 2008; Stracke et al., 2010; Huang et al., 2012; Gangappa and Botto, 2016; Qian et al., 2019). The I box motif is a part of light responsive element and is reported to be present in the upstream regulatory sequences of light regulated genes (Giuliano et al., 1988; Houston et al., 2013; Chao et al., 2014), and the Box 4 motif that is conserved across plants is involved in transcriptional regulation of genes associated with light stress (Chao et al., 2014). In MIR775 promoter sequence, the Box-4 motifs were present at 238nts and 253nts upstream of the TSS, while other two light responsive motifs were present singly. However, when we exposed the WT plants to high light conditions $\left(600 \mu \mathrm{mol} / \mathrm{m}^{2} / \mathrm{sec}\right.$ and 1000 
267

268

269

270

271

272

273

274

275

276

277

278

279

280

281

282

283

284

285

286

287

288

289

290

291

292

293

294

295

296

$\mu \mathrm{mol} / \mathrm{m}^{2} / \mathrm{sec}$ ) for one hour, we could not detect any significant difference in expression level of miR775 (Fig. 4B). Further, considering the prevalence of UV-B in high altitude area and some of the light responsive elements are UV-responsive (like the ACE present in promoter of MIR775), expression of miR775 was analysed from UV-B treated plants. Interestingly, a significant increase in the expression of miR775 was observed in post UV-B treated plants (Fig. 4C).

Besides light responsive elements, there are three ARE and one ATCTA elements in the promoter region of MIR775. The ARE and ATCTA elements are reported to be present in the promoter of Alchohol Dehydrogenase 1, a hypoxia responsive gene (Walker et al., 1987; Dolferus et al., 1994; Hinz et al., 2010). The presence of three ARE motifs, with one in the immediate vicinity of the TSS suggested a strong influence of this motif in governing MIR775 promoter activity. We tested the expression of miR775 under hypoxic condition by treating the plants with mitochondrial respiratory inhibitors. The data suggested treatment with mitochondrial inhibitors led to an increase in miR775 level (Fig. 4D). Further, we determined the level of hydrogen peroxide under hypoxic conditions in WT, MIR775OXP and target mutant. After six hours of treatment with mitochondrial inhibitors, hydrogen peroxide accumulation was more in the target mutant and MIR775OXP as compared to the WT (Supplementary Fig. 4). This suggests that reduced level of the target gene in both target mutant and MIR775OXP promotes hydrogen peroxide accumulation in response to hypoxia.

\section{4. miR775 affects rosette size}

To determine the role of miR775 in plant growth and development, WT, MIR775OXP and target mutant plants were phenotypically characterized. The rosette area was significantly higher in MIR775OXP and the target mutant as compared to WT, 20 days post-germination (Fig. 5A, 5B, Supplementary Table 4). This was mainly due to expanded leaves with elongated petiole in MIR775OXP and the target mutant as compared to the WT (Fig. 5C, 5D). The rosette area of the target mutant was higher than the MIR775OXP. Interestingly, the number of rosette leaves was more in target mutant than WT, though there was no significant difference in rosette leaf number between MIR775OXP and WT (Fig. 5D). There were no significant variations in bolting time, plant height or total number of siliques in the target mutant and MIR775OXP as compared to WT. Although the target mutant had longer silique size and more number of seeds per silique than WT, but no difference was observed between MIR775OXP and WT (Fig. 5E). These results 
indicate prominent effect of miR775 in influencing rosette size, but relative miR775/target stoichiometry may not favour its tight regulation of reproductive traits.

\section{5. miR775 targeted $\beta$-(1,3)-galactosyltransferase may be involved in complex carbohydrate biosynthesis}

The $\beta$-(1,3)-galactosyltransferases are reported to be involved in the formation $\beta-(1,3)$ galactan content of arabinogalactan proteins (AGPs) and rhamnogalacturonan I (RG-I), a pectin glycan (Qu et al. 2008 ;Showalter and Basu 2016; Suzuki et al. 2017). Further, using STRING tool (https://string-db.org/) (Szklarczyk et al., 2015; Szklarczyk et al., 2019), the target $\beta$-(1,3)galactosyltransferase was predicted to be functionally associate with proteins involved in protein glycosylation, complex carbohydrate biosynthesis and cell wall biogenesis (Supplementary Fig. 5, Supplementary Table 5). Thus it was speculated that the target GALT may be involved in regulation of the $\beta$-(1,3)-galactan content of arabinogalactans. The qualitative test of arabinogalactans using $\beta$-Gal-Yariv staining showed there was marked difference in staining intensity in stem cross sections of the WT and the null mutant of the target gene, but not between the MIR775OXP and WT (Fig. 6A, Supplementary Fig. 6A). However, there was no difference in $\beta$-Gal-Yariv staining intensity in the pollen grains of both target mutant and MIR775OXP as compared to WT (Supplementary Fig. 6B). Galactosyltransferases are reported to cause variation in seed coat phenotype by altering the properties of the seed coat mucilage (Basu et al., 2015a; Basu et al., 2015b). Therefore, the seed coat phenotype was analysed by staining with calcofluor white and visualized under confocal microscope. As evident the target mutant exhibited reduced staining as compared to WT and MIR775OXP (Fig. 6B). As observed with $\beta$-Gal-Yariv staining, there was no observable variation between MIR775OXP and WT on calcoflour white staining. Altogether, these results suggest that the target gene of miR775 is possibly involved in governing the biosynthesis of complex carbohydrates.

\section{Discussion}

MicroRNAs have evolved as subtle regulators of gene expression. Recently, a few nonconserved miRNAs having a significant role in plant growth and development have been identified. The miR775 is considered to be a non-conserved, newly evolved miRNA in $A$. thaliana (Rajagopalan et al., 2006). A few studies have reported that the expression of miR775 is 
altered under stressed conditions (Moldovan et al., 2010; Liang et al., 2015). However, the regulatory mechanism of miR775 is still unexplored.

We observed ubiquitous expression of miR775 under standard growth condition. However, under UV and hypoxic conditions expression of miR775 was increased. The analysis of putative promoter sequence of MIR775 indeed suggested presence of different stress responsive elements including light and/or UV light which are prevalent in high altitude areas. Recently, Zhang et al. (2021) reported that HY5 negatively regulates the expression of miR775. However, we did not observe down-regulation of miR775 under experimental light conditions. The high altitude populations are exposed to high UV light and other abiotic stress conditions (Körner, 2007). The increased expression of miR775 might be an adaptive strategy of the plants in high altitude areas. Besides light related motifs, we also observed enrichment of hypoxia related motifs in the MIR775 promoter sequence. Thus, as expected the expression of miR775 was elevated under hypoxic condition as compared to the control. Earlier study, while analysing hypoxia responsive miRNAs, also observed increased expression of miR775 under hypoxic condition (Moldovan et al., 2009). The partial atmospheric pressure is generally less in high altitude areas as compared to sea level. It is reported that hydrogen peroxide is involved in hypoxia signalling and thereby regulating response to hypoxia (Blokhina et al., 2001; Vergara et al., 2012; Yang, 2014). Moreover, a genome wide study also indicated down-regulation of the validated target gene of miR775 (discussed below) under hypoxic condition (Branco-Price et al., 2005). Thus we observed more accumulation of hydrogen peroxide in the target mutant and MIR775OXP as compared to the WT. It will be interesting to investigate the regulatory mechanisms of miR775 that might aid high altitude populations to adapt under hypoxic condition.

miRNAs exerts their effect by regulating target genes. Our in-silico target analyses predicted a galactosyltransferase gene as the target of miR775 which was further confirmed experimentally using modified 5'RLM-RACE. Zhang et al. (2021) also reported the same gene as the target of miR775. However, while they reported cleavage of target as unconventional, being deviated from conventional cleavage site between $10^{\text {th }}$ and $11^{\text {th }}$ position of complementarity, our data shows perfect cleavage of the target by the miR775. Galactosyltransferases are reported to participate in the assembly of various complex polysaccharides and proteoglycans by adding galactose to various glycol-conjugates (Velasquez et al., 2011; Qin et al., 2017)). Further, 
galactosyltransferases are reported to be involved in growth and developmental processes (Velasquez et al., 2011; Geshi et al., 2013; Basu et al., 2015a; Basu et al., 2015b; Showalter and Basu, 2016; Qin et al., 2017; Suzuki et al., 2017). Our phylogenetic analysis suggested the target GALT is a probable $\beta$-(1,3)-galactosyltransferase. The biological role of different $\beta-(1,3)$ galactosyltransferases have been reported. For example, GhGalT1, a $\beta$-(1,3)galactosyltransferase in cotton plays critical role in regulating cotton fibre development by controlling the glycosylation of AGPs (Qin et al., 2017) and KNS4/UPEX1, another GT31 family member is reported to be involved in regulating arabinogalactan biosynthesis and pollen development in A. thaliana (Suzuki et al., 2017). Differential staining by $\beta$-Gal-Yariv reagent, a phenylglycoside that is known to specifically bind to the $\beta-(1,3)$ - galactan chains (Kitazawa et al., 2013) suggests that the target gene of miR775 is likely involved in regulating the $\beta-(1,3)$ galactan content of arabinogalactans in the stem. Besides, it is also reported that GT31 family members govern the properties of seed coat mucilage by regulating formation of complex carbohydrate (Basu et al., 2015a; Basu et al., 2015b). Differential staining of seed coat of the target mutant and WT plants with calcofluor white also suggests the target GALT might affect seed coat mucilage.

Recently, it has been reported that miR775 may regulate cell and organ size in $A$. thaliana by cell wall remodelling involving complex polysaccharides (Zhang et al., 2021). In our study, differential staining of stem cross-section and seed coat between target mutant and WT also suggest differential composition of cell wall components. Differential staining of stem cross-section and/ or seed coat between target mutant and WT also suggest differential composition of complex polysaccharides in these organs.

Although we did not carry out detailed mechanisms, but our phenotypic assessment of the target mutant and MIR775OXP also suggest putative role of miR775 in plant growth and development, particularly in regulating rosette size. Importantly, the effect of target downregulation was more prominent in vegetative growth stage as compared to the reproductive traits. Moreover, as expected the knockout effect of the target gene on manifestation of traits was more prominent as compared to the down-regulation of the target by miR775. This was clearly evident when there was no difference in trait manifestation between MIR775OXP and the WT. For example, there was no difference in silique length and seed number per silique or $\beta$-Gal-Yariv 
differences between the knockout mutant and WT. It may be that the relative stoichiometry of miR775/target is not quantitatively enough for such trait manifestation.

\section{Conclusions}

We describe the functional significance of miR775, an evolutionary young miRNA that targets a probable $\beta$-(1,3)-galactosyltransferase. Both, miR775 and its target gene are ubiquitously expressed having a more pronounced role during vegetative growth leading to increased rosette area. Increased expression of miR775 under UV light and hypoxia intuitively suggest it might aid in high altitude adaptation of plants, since these are more prevalent in these area. However, detailed studies need to be conducted to decipher any role of miR775 in plant adaptation in high altitude areas. Nevertheless, our findings high lights the significance of a young miRNA in plant growth and development. Since miR775 is only reported in A. thaliana while galactosyltransferases are conserved, the significance of newly evolved young miRNAs in regulating galactosyltransferases needs to be analysed in other plant species.

\section{Acknowledgment}

The authors acknowledge the financial support of Council of Scientific and Industrial Research (CSIR), New Delhi and partly by Department of Biotechnology (DBT), Government of India, New Delhi, India. PM and AKV also acknowledge the University Grant Commission (UGC), New Delhi for providing the fellowship.

The institutional ethic committee reference number for the manuscript is CSIRNBRI_MS/2021/01/05.

\section{Author contribution}

PM, AS, AKV and RS conducted experiments. PM analysed the results and wrote the manuscript with SR. SR designed and arranged fund for the experiments.

\section{References}

Achard, P., Herr, A., Baulcombe, D.C. and Harberd, N.P., 2004. Modulation of floral development by a gibberellin-regulated microRNA. Development 131, 3357-3365.

Alexieva, V., Sergiev, I., Mapelli, S. and Karanov, E., 2001. The effect of drought and ultraviolet radiation on growth and stress markers in pea and wheat. Plant, Cell \& Environment 24, 1337-1344.

Bartel, D.P., 2004. MicroRNAs: genomics, biogenesis, mechanism, and function. cell 116, 281-297. 
Basu, D., Tian, L., Wang, W., Bobbs, S., Herock, H., Travers, A. and Showalter, A.M., 2015a. A small multigene hydroxyproline-O-galactosyltransferase family functions in arabinogalactan-protein glycosylation, growth and development in Arabidopsis. BMC plant biology 15, 295.

Basu, D., Wang, W., Ma, S., DeBrosse, T., Poirier, E., Emch, K., Soukup, E., Tian, L. and Showalter, A.M., 2015b. Two hydroxyproline galactosyltransferases, GALT5 and GALT2, function in arabinogalactan-protein glycosylation, growth and development in Arabidopsis. PLoS One 10, e0125624.

Bond, D.M., Wilson, I.W., Dennis, E.S., Pogson, B.J. and Jean Finnegan, E., 2009. VERNALIZATION INSENSITIVE 3 (VIN3) is required for the response of Arabidopsis thaliana seedlings exposed to low oxygen conditions. The Plant Journal 59, 576-587.

Branco-Price, C., Kawaguchi, R., Ferreira, R.B. and Bailey-Serres, J., 2005. Genome-wide analysis of transcript abundance and translation in Arabidopsis seedlings subjected to oxygen deprivation. Annals of botany $96,647-660$.

Chao, M., Yin, Z., Hao, D., Zhang, J., Song, H., Ning, A., Xu, X. and Yu, D., 2014. Variation in Rubisco activase (RCA $\beta$ ) gene promoters and expression in soybean [Glycine max (L.) Merr.]. Journal of experimental botany 65, 47-59.

Chen, H.-M., Chen, L.-T., Patel, K., Li, Y.-H., Baulcombe, D.C. and Wu, S.-H., 2010. 22-Nucleotide RNAs trigger secondary siRNA biogenesis in plants. Proceedings of the National Academy of Sciences 107, 15269-15274.

Chiou, T.-J., Aung, K., Lin, S.-I., Wu, C.-C., Chiang, S.-F. and Su, C.-I., 2006. Regulation of phosphate homeostasis by microRNA in Arabidopsis. The Plant Cell 18, 412-421.

Chung, P.J., Park, B.S., Wang, H., Liu, J., Jang, I.-C. and Chua, N.-H., 2016. Light-inducible miR163 targets PXMT1 transcripts to promote seed germination and primary root elongation in Arabidopsis. Plant physiology 170, 1772-1782.

Clough, S.J. and Bent, A.F., 1998. Floral dip: a simplified method for Agrobacterium-mediated transformation of Arabidopsis thaliana. The plant journal 16, 735-743.

Cuperus, J.T., Carbonell, A., Fahlgren, N., Garcia-Ruiz, H., Burke, R.T., Takeda, A., Sullivan, C.M., Gilbert, S.D., Montgomery, T.A. and Carrington, J.C., 2010. Unique functionality of 22-nt miRNAs in triggering RDR6-dependent siRNA biogenesis from target transcripts in Arabidopsis. Nature structural \& molecular biology 17, 997.

Cuperus, J.T., Fahlgren, N. and Carrington, J.C., 2011. Evolution and functional diversification of MIRNA genes. The Plant Cell 23, 431-442.

Dai, X. and Zhao, P.X., 2011. psRNATarget: a plant small RNA target analysis server. Nucleic acids research 39, W155-W159.

Daudi, A. and O'Brien, J.A., 2012. Detection of hydrogen peroxide by DAB staining in Arabidopsis leaves. Bio Protoc 2, 1-4.

Dereeper, A., Guignon, V., Blanc, G., Audic, S., Buffet, S., Chevenet, F., Dufayard, J.-F., Guindon, S., Lefort, V. and Lescot, M., 2008. Phylogeny. fr: robust phylogenetic analysis for the nonspecialist. Nucleic acids research 36, W465-W469.

Dolferus, R., Jacobs, M., Peacock, W.J. and Dennis, E.S., 1994. Differential interactions of promoter elements in stress responses of the Arabidopsis Adh gene. Plant Physiology 105, 1075-1087.

Eckardt, N.A., 2012. A microRNA cascade in plant defense. Am Soc Plant Biol.

Fahlgren, N., Howell, M.D., Kasschau, K.D., Chapman, E.J., Sullivan, C.M., Cumbie, J.S., Givan, S.A., Law, T.F., Grant, S.R. and Dangl, J.L., 2007. High-throughput sequencing of Arabidopsis microRNAs: evidence for frequent birth and death of MIRNA genes. PloS one 2, e219.

Felippes, F.F. and Weigel, D., 2009. Triggering the formation of tasiRNAs in Arabidopsis thaliana: the role of microRNA miR173. EMBO reports 10, 264-270. 
Gangappa, S.N. and Botto, J.F., 2016. The multifaceted roles of HY5 in plant growth and development. Molecular plant 9, 1353-1365.

Geshi, N., Johansen, J.N., Dilokpimol, A., Rolland, A., Belcram, K., Verger, S., Kotake, T., Tsumuraya, Y., Kaneko, S. and Tryfona, T., 2013. A galactosyltransferase acting on arabinogalactan protein glycans is essential for embryo development in A rabidopsis. The Plant Journal 76, 128-137.

Giuliano, G., Pichersky, E., Malik, V., Timko, M., Scolnik, P. and Cashmore, A., 1988. An evolutionarily conserved protein binding sequence upstream of a plant light-regulated gene. Proceedings of the National Academy of Sciences 85, 7089-7093.

Guo, H.-S., Xie, Q., Fei, J.-F. and Chua, N.-H., 2005. MicroRNA directs mRNA cleavage of the transcription factor NAC1 to downregulate auxin signals for Arabidopsis lateral root development. The Plant Cell 17, 1376-1386.

Hinz, M., Wilson, I.W., Yang, J., Buerstenbinder, K., Llewellyn, D., Dennis, E.S., Sauter, M. and Dolferus, R., 2010. Arabidopsis RAP2. 2: an ethylene response transcription factor that is important for hypoxia survival. Plant physiology 153, 757-772.

Houston, K., McKim, S.M., Comadran, J., Bonar, N., Druka, I., Uzrek, N., Cirillo, E., Guzy-Wrobelska, J., Collins, N.C. and Halpin, C., 2013. Variation in the interaction between alleles of HvAPETALA2 and microRNA172 determines the density of grains on the barley inflorescence. Proceedings of the National Academy of Sciences 110, 16675-16680.

Huang, X., Ouyang, X., Yang, P., Lau, O.S., Li, G., Li, J., Chen, H. and Deng, X.W., 2012. Arabidopsis FHY3 and HY5 positively mediate induction of COP1 transcription in response to photomorphogenic UV-B light. The Plant Cell 24, 4590-4606.

Jefferson, R., 1989. The GUS reporter gene system. Nature 342, 837-838.

Kawashima, C.G., Matthewman, C.A., Huang, S., Lee, B.R., Yoshimoto, N., Koprivova, A., Rubio-Somoza, I., Todesco, M., Rathjen, T. and Saito, K., 2011. Interplay of SLIM1 and miR395 in the regulation of sulfate assimilation in Arabidopsis. The Plant Journal 66, 863-876.

Kitazawa, K., Tryfona, T., Yoshimi, Y., Hayashi, Y., Kawauchi, S., Antonov, L., Tanaka, H., Takahashi, T., Kaneko, S. and Dupree, P., 2013. $\beta$-Galactosyl Yariv reagent binds to the $\beta$-1, 3-galactan of arabinogalactan proteins. Plant Physiology 161, 1117-1126.

Körner, C., 2007. The use of 'altitude' in ecological research. Trends in ecology \& evolution 22, 569-574.

Koyama, T., Mitsuda, N., Seki, M., Shinozaki, K. and Ohme-Takagi, M., 2010. TCP transcription factors regulate the activities of ASYMMETRIC LEAVES1 and miR164, as well as the auxin response, during differentiation of leaves in Arabidopsis. The Plant Cell 22, 3574-3588.

Koyama, T., Sato, F. and Ohme-Takagi, M., 2017. Roles of miR319 and TCP transcription factors in leaf development. Plant physiology 175, 874-885.

Liang, G., Ai, Q. and Yu, D., 2015. Uncovering miRNAs involved in crosstalk between nutrient deficiencies in Arabidopsis. Scientific reports 5, 11813.

Liang, G., Yang, F. and Yu, D., 2010. MicroRNA395 mediates regulation of sulfate accumulation and allocation in Arabidopsis thaliana. The Plant Journal 62, 1046-1057.

Logemann, E. and Hahlbrock, K., 2002. Crosstalk among stress responses in plants: pathogen defense overrides UV protection through an inversely regulated ACE/ACE type of light-responsive gene promoter unit. Proceedings of the National Academy of Sciences 99, 2428-2432.

Lu, C., Kulkarni, K., Souret, F.F., MuthuValliappan, R., Tej, S.S., Poethig, R.S., Henderson, I.R., Jacobsen, S.E., Wang, W. and Green, P.J., 2006. MicroRNAs and other small RNAs enriched in the Arabidopsis RNA-dependent RNA polymerase-2 mutant. Genome research 16, 1276-1288.

Lv, D.-K., Bai, X., Li, Y., Ding, X.-D., Ge, Y., Cai, H., Ji, W., Wu, N. and Zhu, Y.-M., 2010. Profiling of coldstress-responsive miRNAs in rice by microarrays. Gene 459, 39-47.

Ma, Z., Jiang, J., Hu, Z., Lyu, T., Yang, Y., Jiang, J. and Cao, J., 2017. Over-expression of miR158 causes pollen abortion in Brassica campestris ssp. chinensis. Plant molecular biology 93, 313-326. 
Mallory, A.C., Bartel, D.P. and Bartel, B., 2005. MicroRNA-directed regulation of Arabidopsis AUXIN RESPONSE FACTOR17 is essential for proper development and modulates expression of early auxin response genes. The Plant Cell 17, 1360-1375.

Marin, E., Jouannet, V., Herz, A., Lokerse, A.S., Weijers, D., Vaucheret, H., Nussaume, L., Crespi, M.D. and Maizel, A., 2010. miR390, Arabidopsis TAS3 tasiRNAs, and their AUXIN RESPONSE FACTOR targets define an autoregulatory network quantitatively regulating lateral root growth. The Plant Cell 22, 1104-1117.

Moldovan, D., Spriggs, A., Yang, J., Pogson, B.J., Dennis, E.S. and Wilson, I.W., 2010. Hypoxia-responsive microRNAs and trans-acting small interfering RNAs in Arabidopsis. Journal of experimental botany 61, 165-177.

Montgomery, T.A., Yoo, S.J., Fahlgren, N., Gilbert, S.D., Howell, M.D., Sullivan, C.M., Alexander, A., Nguyen, G., Allen, E. and Ahn, J.H., 2008. AGO1-miR173 complex initiates phased siRNA formation in plants. Proceedings of the National Academy of Sciences 105, 20055-20062.

Nag, A., King, S. and Jack, T., 2009. miR319a targeting of TCP4 is critical for petal growth and development in Arabidopsis. Proceedings of the National Academy of Sciences 106, 2253422539.

Popper, Z.A., 2011. Extraction and detection of arabinogalactan proteins, The Plant Cell Wall. Springer, pp. 245-254.

Qian, M., Kalbina, I., Rosenqvist, E., Jansen, M.A., Teng, Y. and Strid, Å., 2019. UV regulates the expression of phenylpropanoid biosynthesis genes in cucumber (Cucumis sativus L.) in an organ and spectrum dependent manner. Photochemical \& Photobiological Sciences 18, 424-433.

Qin, L.X., Chen, Y., Zeng, W., Li, Y., Gao, L., Li, D.D., Bacic, A., Xu, W.L. and Li, X.B., 2017. The cotton $\beta$ galactosyltransferase 1 (GalT1) that galactosylates arabinogalactan proteins participates in controlling fiber development. The Plant Journal 89, 957-971.

Qu, Y., Egelund, J., Gilson, P.R., Houghton, F., Gleeson, P.A., Schultz, C.J. and Bacic, A., 2008. Identification of a novel group of putative Arabidopsis thaliana $\beta-(1,3)$-galactosyltransferases. Plant molecular biology 68, 43-59.

Rajagopalan, R., Vaucheret, H., Trejo, J. and Bartel, D.P., 2006. A diverse and evolutionarily fluid set of microRNAs in Arabidopsis thaliana. Genes \& development 20, 3407-3425.

Reinhart, B.J., Weinstein, E.G., Rhoades, M.W., Bartel, B. and Bartel, D.P., 2002. MicroRNAs in plants. Genes \& development 16, 1616-1626.

Rodriguez, R.E., Mecchia, M.A., Debernardi, J.M., Schommer, C., Weigel, D. and Palatnik, J.F., 2010. Control of cell proliferation in Arabidopsis thaliana by microRNA miR396. Development 137, 103-112.

Safrany, J., Haasz, V., Mate, Z., Ciolfi, A., Feher, B., Oravecz, A., Stec, A., Dallmann, G., Morelli, G. and Ulm, R., 2008. Identification of a novel cis-regulatory element for UV-B-induced transcription in Arabidopsis. The Plant Journal 54, 402-414.

Schmittgen, T.D. and Livak, K.J., 2008. Analyzing real-time PCR data by the comparative C T method. Nature protocols 3, 1101.

Sharma, D., Tiwari, M., Pandey, A., Bhatia, C., Sharma, A. and Trivedi, P.K., 2016. MicroRNA858 is a potential regulator of phenylpropanoid pathway and plant development. Plant physiology 171, 944-959.

Showalter, A.M. and Basu, D., 2016. Glycosylation of arabinogalactan-proteins essential for development in Arabidopsis. Communicative \& integrative biology 9, e0125624.

Stracke, R., FAVORY, J.J., Gruber, H., Bartelniewoehner, L., Bartels, S., Binkert, M., Funk, M., Weisshaar, B. and UIm, R., 2010. The Arabidopsis bZIP transcription factor HY5 regulates expression of the $\mathrm{PFG1/MYB12}$ gene in response to light and ultraviolet-B radiation. Plant, cell \& environment 33, 88-103. 
Strasser, R., Bondili, J.S., Vavra, U., Schoberer, J., Svoboda, B., Glössl, J., Léonard, R., Stadlmann, J., Altmann, F. and Steinkellner, H., 2007. A unique B1, 3-galactosyltransferase is indispensable for the biosynthesis of $\mathrm{N}$-glycans containing Lewis a structures in Arabidopsis thaliana. The Plant Cell 19, 2278-2292.

Sunkar, R. and Zhu, J.-K., 2004. Novel and stress-regulated microRNAs and other small RNAs from Arabidopsis. The Plant Cell 16, 2001-2019.

Suzuki, T., Narciso, J.O., Zeng, W., van de Meene, A., Yasutomi, M., Takemura, S., Lampugnani, E.R., Doblin, M.S., Bacic, A. and Ishiguro, S., 2017. KNS4/UPEX1: a type II arabinogalactan $\beta-(1,3)-$ galactosyltransferase required for pollen exine development. Plant Physiology 173, 183-205.

Szklarczyk, D., Franceschini, A., Wyder, S., Forslund, K., Heller, D., Huerta-Cepas, J., Simonovic, M., Roth, A., Santos, A. and Tsafou, K.P., 2015. STRING v10: protein-protein interaction networks, integrated over the tree of life. Nucleic acids research 43, D447-D452.

Szklarczyk, D., Gable, A.L., Lyon, D., Junge, A., Wyder, S., Huerta-Cepas, J., Simonovic, M., Doncheva, N.T., Morris, J.H. and Bork, P., 2019. STRING v11: protein-protein association networks with increased coverage, supporting functional discovery in genome-wide experimental datasets. Nucleic acids research 47, D607-D613.

Team, R.C., 2017. R: A Language and Environment for Statistical Computing. 887 R Foundation for Statistical Computing, Vienna, Austria. URL https://www 888.

Tripathi, A.M., Singh, A., Singh, R., Verma, A.K. and Roy, S., 2019. Modulation of miRNA expression in natural populations of $A$. thaliana along a wide altitudinal gradient of Indian Himalayas. Scientific reports 9, 1-16.

Vaucheret, H., 2008. Plant argonautes. Trends in plant science 13, 350-358.

Vaucheret, H., Vazquez, F., Crété, P. and Bartel, D.P., 2004. The action of ARGONAUTE1 in the miRNA pathway and its regulation by the miRNA pathway are crucial for plant development. Genes \& development 18, 1187-1197.

Velasquez, S.M., Ricardi, M.M., Dorosz, J.G., Fernandez, P.V., Nadra, A.D., Pol-Fachin, L., Egelund, J., Gille, S., Harholt, J. and Ciancia, M., 2011. O-glycosylated cell wall proteins are essential in root hair growth. Science 332, 1401-1403.

Voinnet, O., 2009. Origin, biogenesis, and activity of plant microRNAs. Cell 136, 669-687.

Walker, J.C., Howard, E.A., Dennis, E.S. and Peacock, W.J., 1987. DNA sequences required for anaerobic expression of the maize alcohol dehydrogenase 1 gene. Proceedings of the National Academy of Sciences 84, 6624-6628.

Wang, J.-W., Wang, L.-J., Mao, Y.-B., Cai, W.-J., Xue, H.-W. and Chen, X.-Y., 2005. Control of root cap formation by microRNA-targeted auxin response factors in Arabidopsis. The Plant Cell 17, 22042216.

Willats, W.G., McCartney, L. and Knox, J.P., 2001. In-situ analysis of pectic polysaccharides in seed mucilage and at the root surface of Arabidopsis thaliana. Planta 213, 37-44.

Wu, G. and Poethig, R.S., 2006. Temporal regulation of shoot development in Arabidopsis thaliana by miR156 and its target SPL3. Development 133, 3539-3547.

Wu, M.-F., Tian, Q. and Reed, J.W., 2006. Arabidopsis microRNA167 controls patterns of ARF6 and ARF8 expression, and regulates both female and male reproduction. Development 133, 4211-4218.

Xie, Z., Kasschau, K.D. and Carrington, J.C., 2003. Negative feedback regulation of Dicer-Like1 in Arabidopsis by microRNA-guided mRNA degradation. Current Biology 13, 784-789.

Zhang, H., Guo, Z., Zhuang, Y., Suo, Y., Du, J., Gao, Z., Pan, J., Li, L., Wang, T. and Xiao, L., 2021. MicroRNA775 Regulates Intrinsic Leaf Size and Reduces Cell Wall Pectin Levels by Targeting a Galactosyltransferase Gene in Arabidopsis. The Plant Cell.

Zhang, H. and Li, L., 2013. SQUAMOSA promoter binding protein-like7 regulated microRNA408 is required for vegetative development in A rabidopsis. The Plant Journal 74, 98-109. 
A

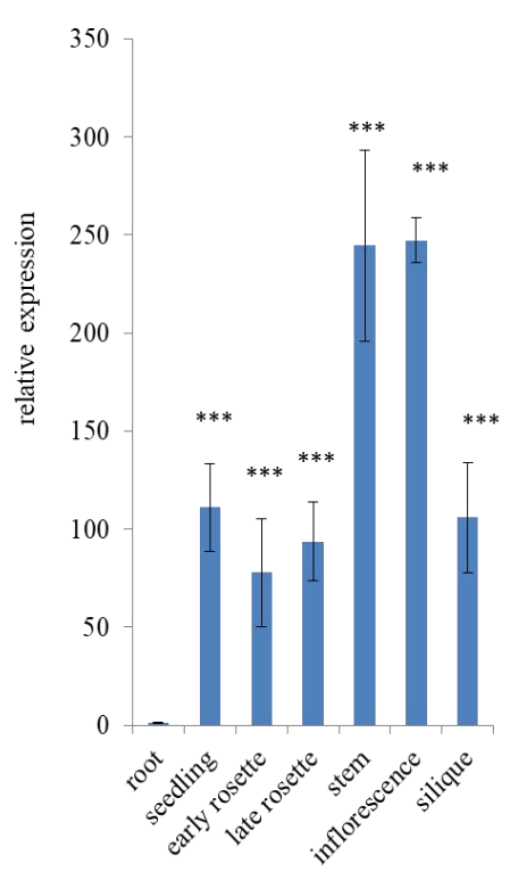

B

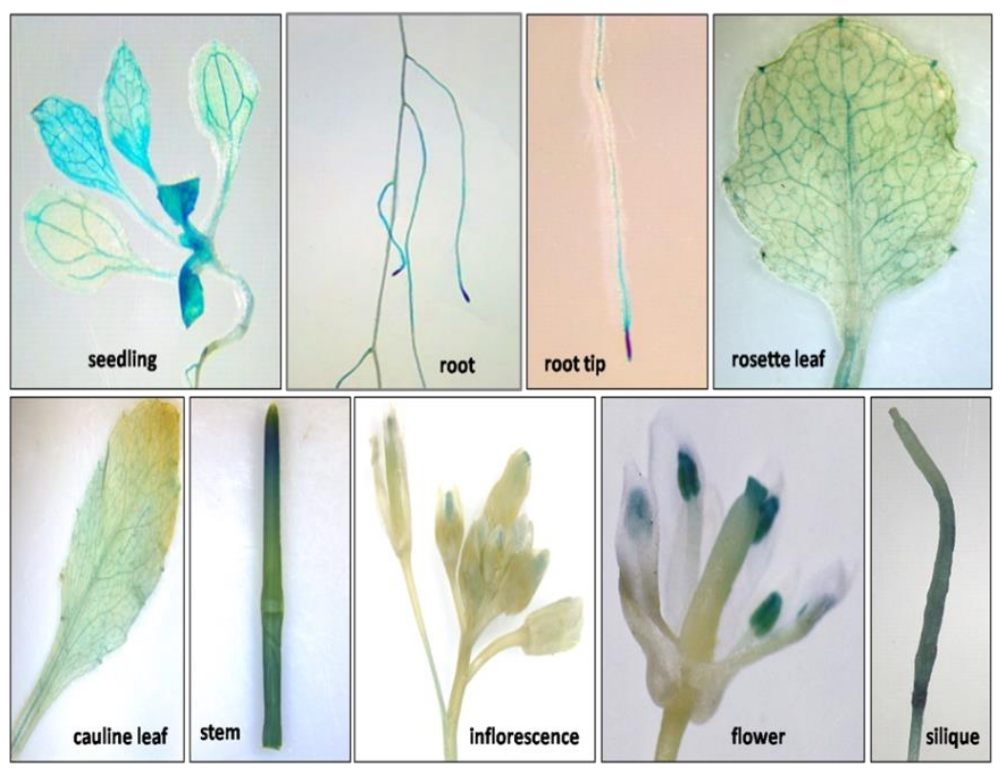

Zhao, Y., Lin, S., Qiu, Z., Cao, D., Wen, J., Deng, X., Wang, X., Lin, J. and Li, X., 2015. MicroRNA857 is involved in the regulation of secondary growth of vascular tissues in Arabidopsis. Plant physiology 169, 2539-2552.

Zhou, L., Liu, Y., Liu, Z., Kong, D., Duan, M. and Luo, L., 2010. Genome-wide identification and analysis of drought-responsive microRNAs in Oryza sativa. Journal of experimental botany 61, 4157-4168.

Fig. 1: Characterization of miR775 in A. thaliana (A) Relative expression of miR775 in different tissues of WT Col-0 as determined by qRT-PCR. Seedling tissue was taken from 1 week old plants, early and late rosette were taken from 15 and 30 days old plants respectively, while root, stem, inflorescence and siliques were collected from 45 days old plants. Data represents mean of three replicates $\pm \mathrm{SE}, * * *$ indicate values which were significantly different at $\mathrm{P}$ value $<0.001$ (Student's t-test). (B) Histochemical GUS staining in different tissues of MIR775PRO-GUS transgenic lines. Seedling and roots tissue were taken from 15 days old plants grown on MS media, rosette leaf was taken from 30 days old plants while cauline leaf, stem, inflorescence, 
A

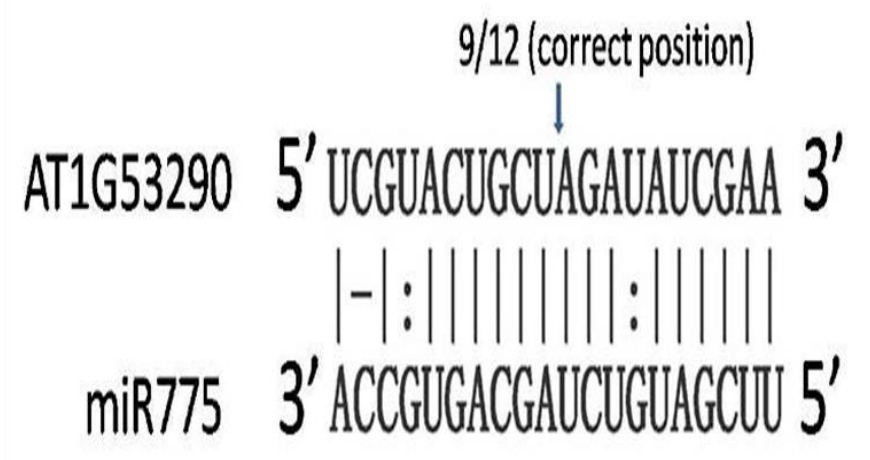

C
B

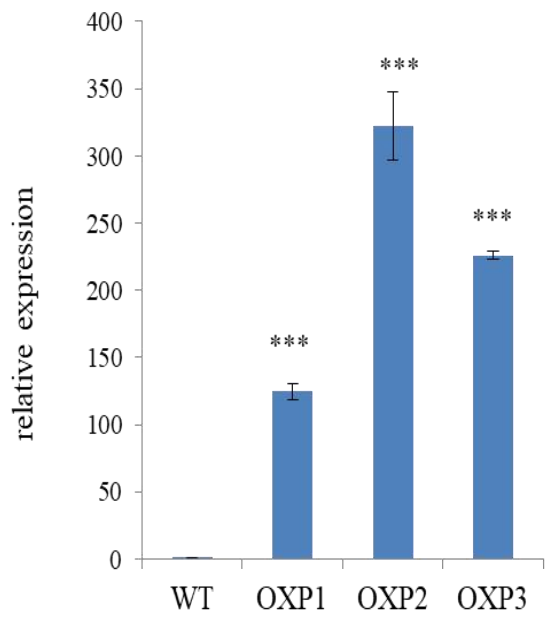

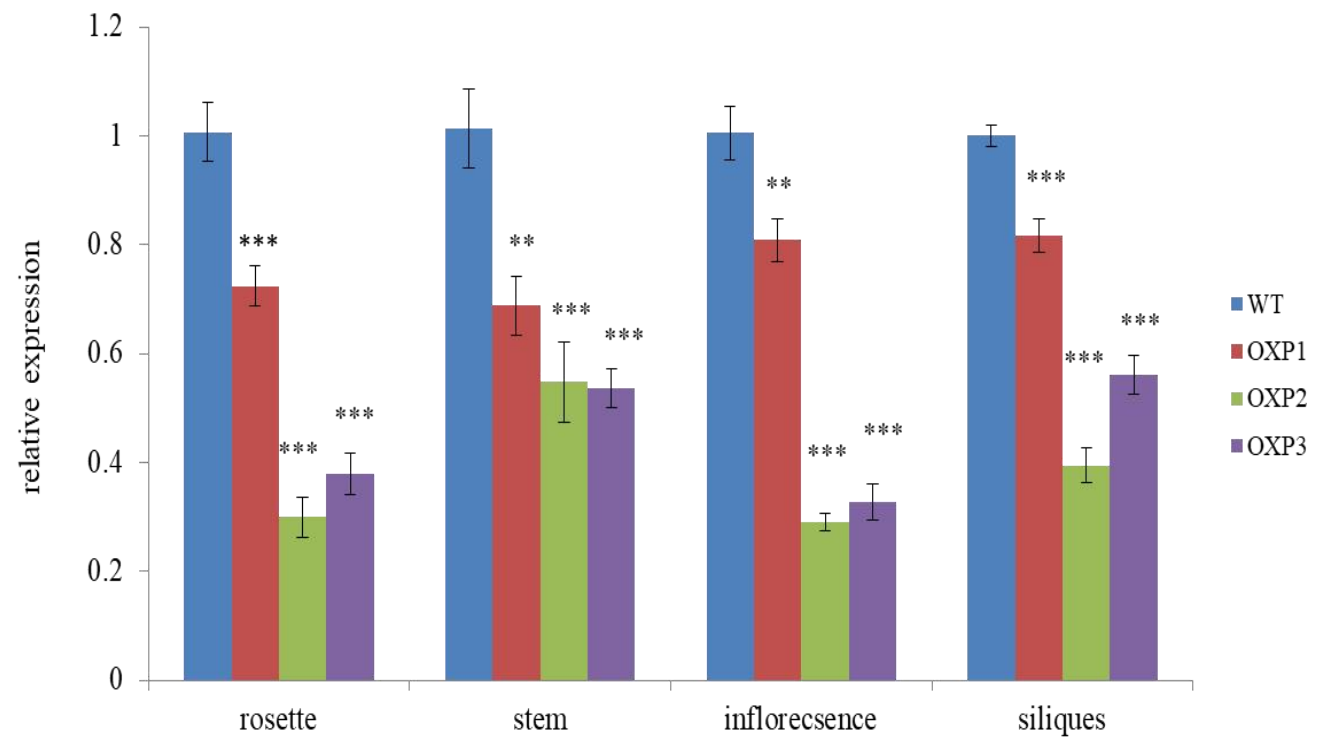

628 Fig. 2: Targeting of AT1G53290 by miR775 (A) Cleavage of AT1G53290 mRNA by miR775 as 629 detected by modified 5'RLM-RACE is shown. The fraction of clones with cleavage at expected 6305 'end to the total number of clones sequenced is indicated above the target site. (B) qRT-PCR 631 analyses of miR775 in rosette tissue of homozygous MIR775OXP lines and WT (C) qRT-PCR 632 analyse of galactosyltransferase target gene (AT1G53290) in rosette, stem, inflorescence and 633 siliques of homozygous MIR775OXP lines and WT. Data is a mean of three replicates \pm SE. **, $634 * * *$ indicate values which were significantly different from WT at $\mathrm{P}$ value $<0.01,<0.001$ 635 respectively (Student's t-test). 


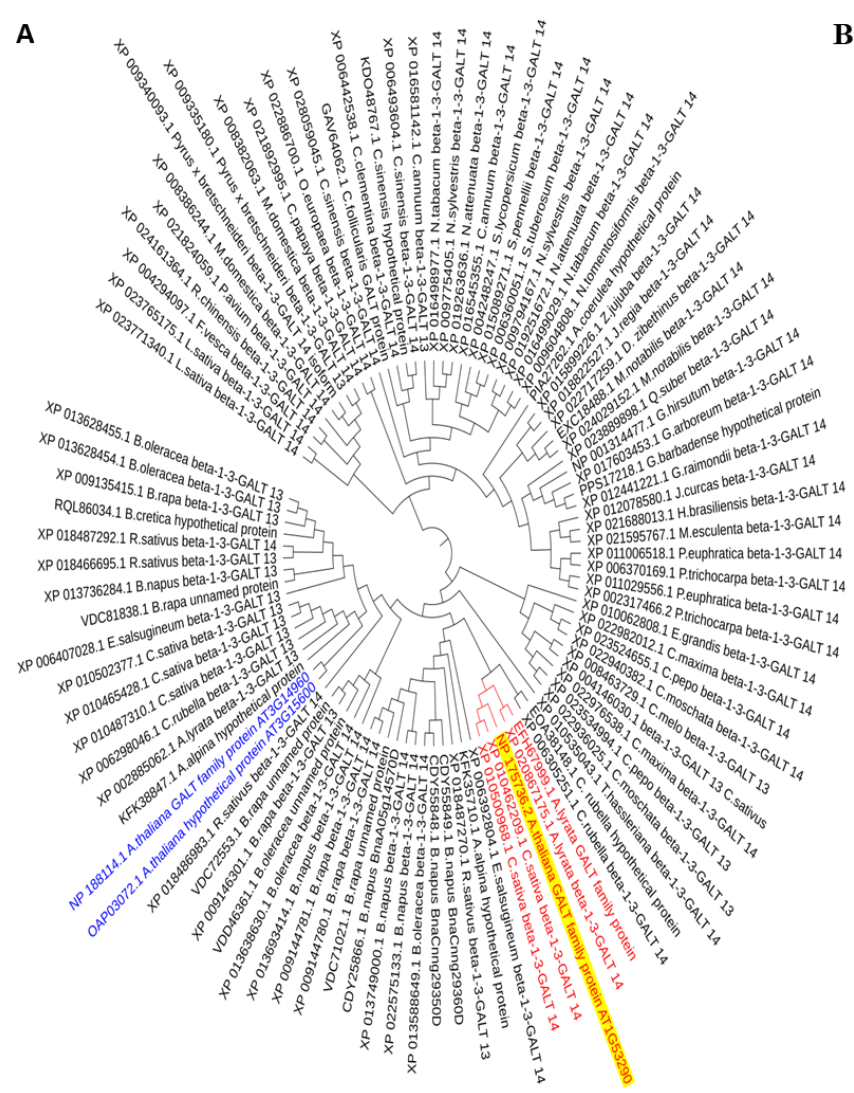

636

637

638

639

640

641

642

643

644

645

646

647

648

649

650 and all members of clade 1 are awaiting functional validation.
B

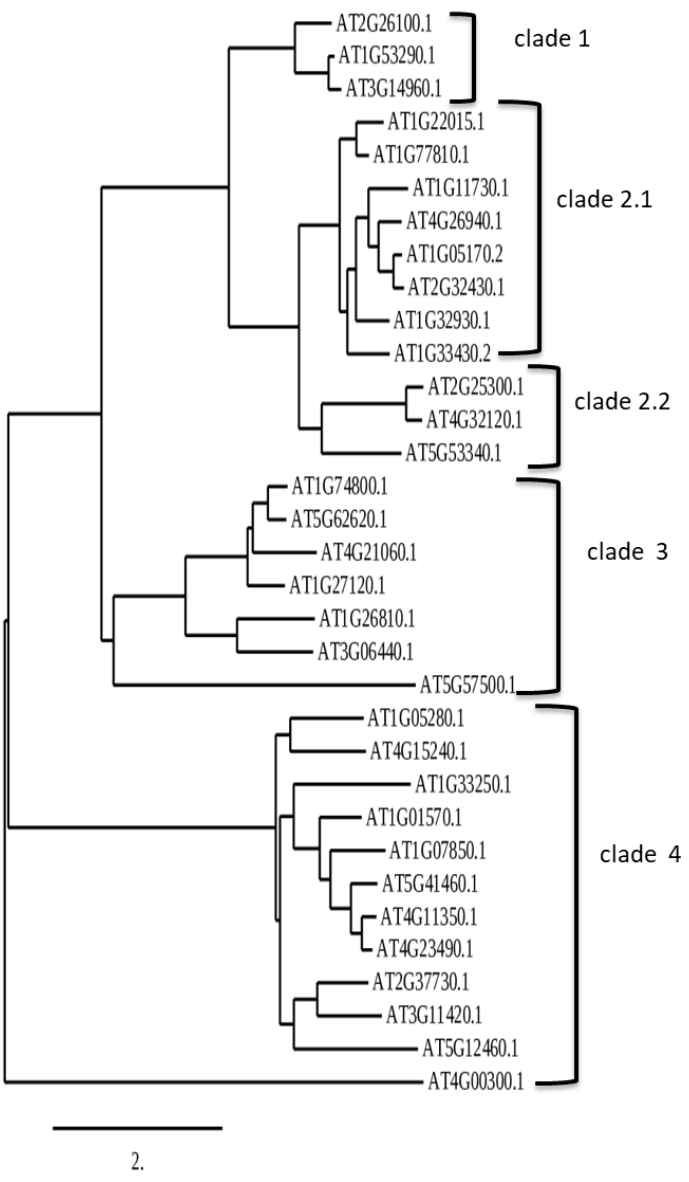

Fig. 3: Characterization of miR775 target gene (A) Phylogenetic analysis of AT1G53290 on the basis of sequence similarity with other plant species (B) Phylogenetic analysis of AT1G53290 with A. thaliana members of GT31 family. All the members of clade 4 and AT5G57500.1 of clade 3 lack the GALT domain (Qu et al., 2008). All other members of clade 3 are hydroxyproline GALTs (Basu et al., 2015a; Basu et al., 2015b), except AT1G26810.1 which is a $\beta$-(1,3)-GALT involved in N-glycan biosynthesis (Strasser et al., 2007). All members of subclade 2.2 are hydroxyproline GALTs (Ogawa-Ohnishi and Matsubayashi, 2015). Members of sub clade 2.1, AT1G87100 and AT1G33430 are $\beta$-(1,3)-GALTs while AT1G32930 is $\beta$-(1,6)GALT (Qu et al., 2008; Geshi et al., 2013; Suzuki et al., 2017). Other members of sub clade 2.1 


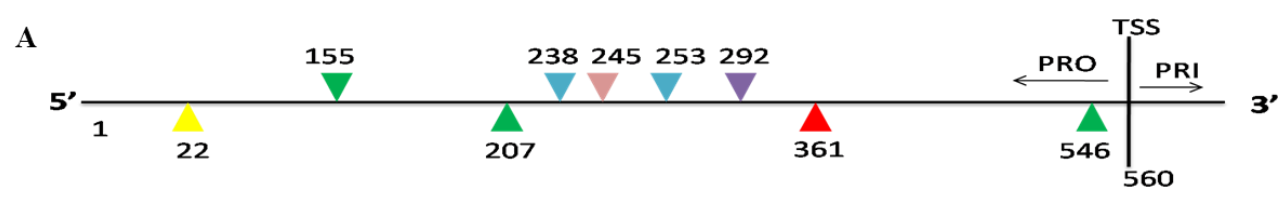
$\triangle \mathrm{ACE}$
$\triangle$ BOX 4
$\triangle$ ARE
I BOX
ATCTA
MBS
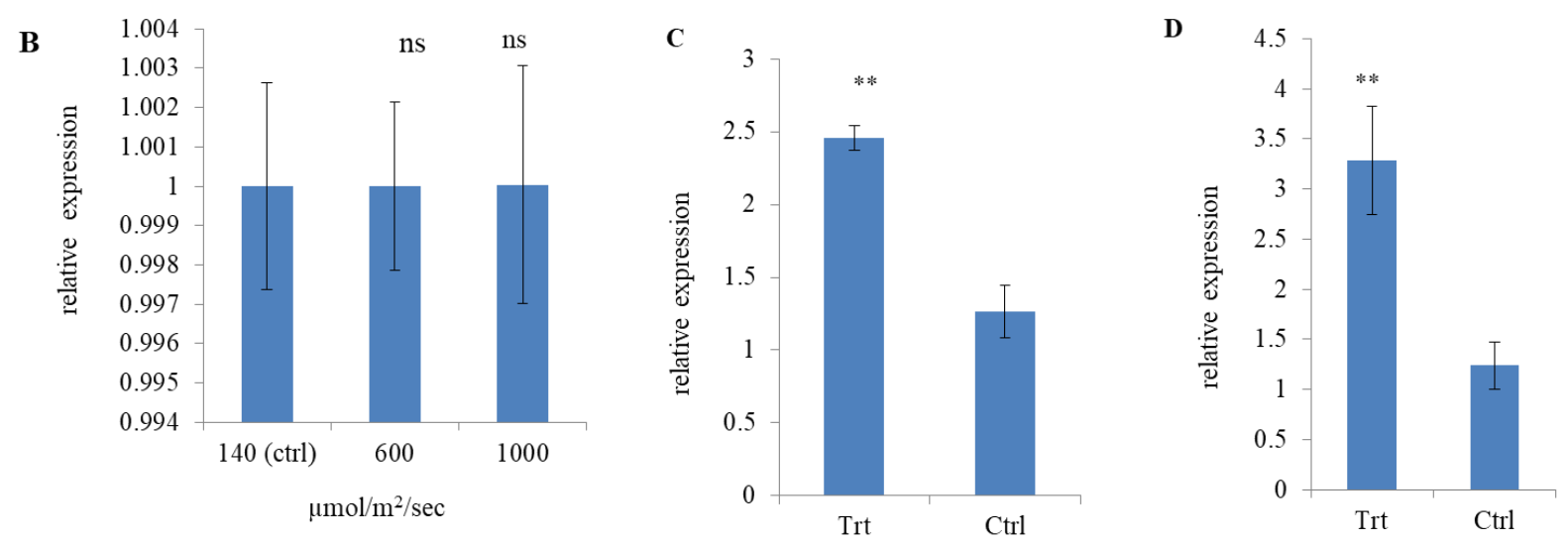

652 Fig 4: Expression of miR775 in response to environmental variables (A) Schematic 653 representation of $M I R 775$ promoter showing regulatory motifs responsive to environmental 654 factors. Real time expression analysis of miR775 (B) after 1 hour of high light treatment (C) 655 after 1 hour of UV-B treatment (D) after 3 hours of treatment with mitochondria inhibitors, 656 Antimycin A and Salicylhydroxamic acid. Data is a mean of three replicates \pm SE. ** indicate 657 values which were significantly different from control with $\mathrm{P}$ value $<0.01$ (Student's t-test), ns 658 indicates non-significant variation with respect to control. 
bioRxiv preprint doi: https://doi.org/10.1101/2021.01.28.428559; this version posted January 28,2021 . The copyright holder for this preprint (which was not certified by peer review) is the author/funder, who has granted bioRxiv a license to display the preprint in perpetuity. It is made available under aCC-BY-NC-ND 4.0 International license.
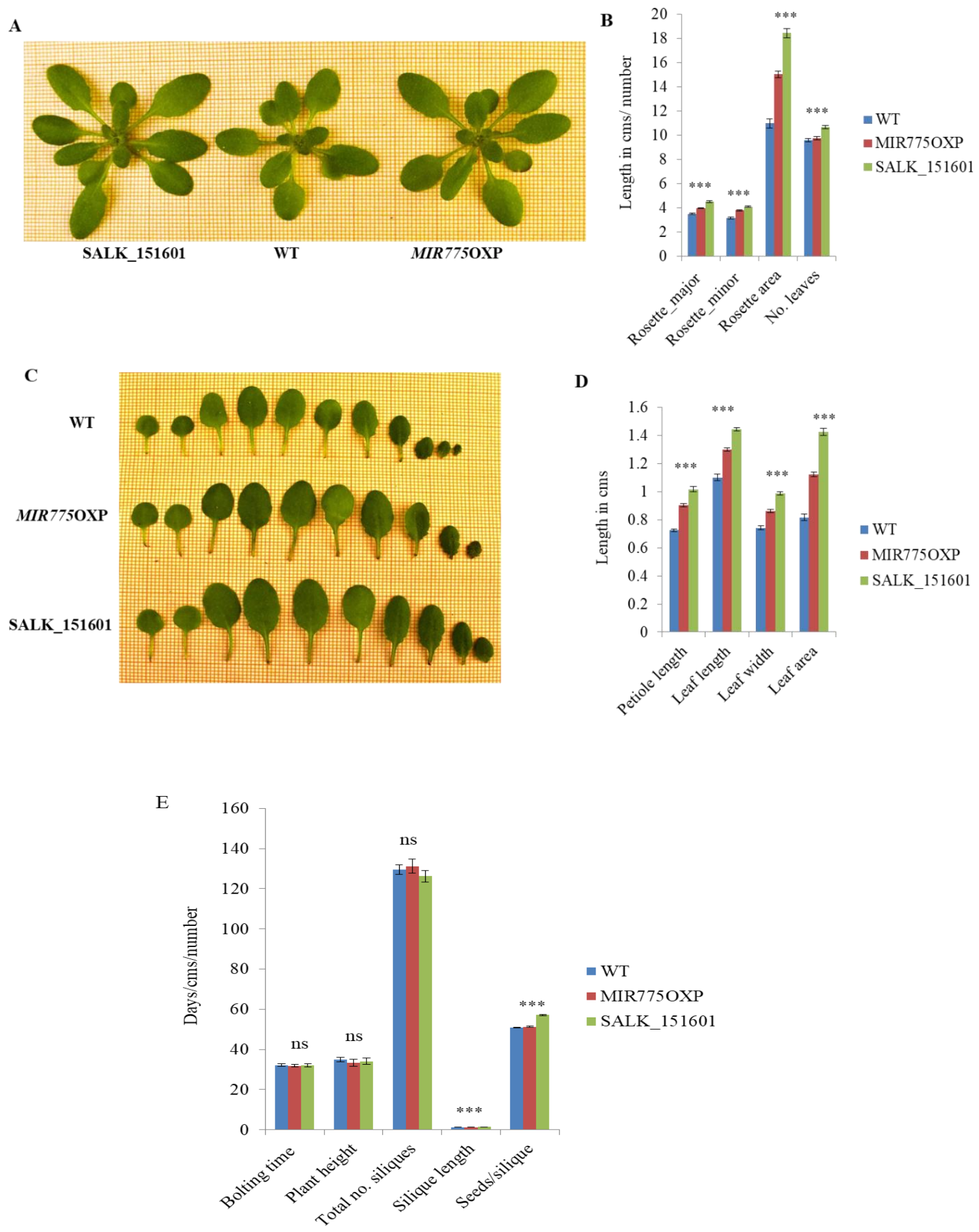

670 Fig. 5: Analyses of morphological traits (A) image showing variation in rosette size (B)

671 graphical representation of rosette parameters showing mean of WT, MIR775OXP, target mutant 
672 (SALK_151601). Error bars represent \pm SE with $n=12$ (C) image showing variation in leaf

673 dimensions (D) graphical representation of leaf parameters showing mean WT, MIR775OXP,

674 target mutant (SALK_151601). Error bars represent \pm SE with $n=12$. (E) Graphical

675 representation of post vegetative traits showing mean of WT, MIR775OXP, target mutant

676 (SALK_151601). Error bars represent \pm SE with $\mathrm{n}=9$. *** indicates significant variations

677 amongst the groups with $\mathrm{p}$ value $<0.001$ according to One Way ANOVA, ns indicates non-

678 significant variation.

679

680

681

682

683

684

685

686

687

688

689

690

691

692

693

694

695

696

697

698

699

700

701

702 
bioRxiv preprint doi: https://doi.org/10.1101/2021.01.28.428559; this version posted January 28,2021 . The copyright holder for this preprint (which was not certified by peer review) is the author/funder, who has granted bioRxiv a license to display the preprint in perpetuity. It is made available under aCC-BY-NC-ND 4.0 International license.

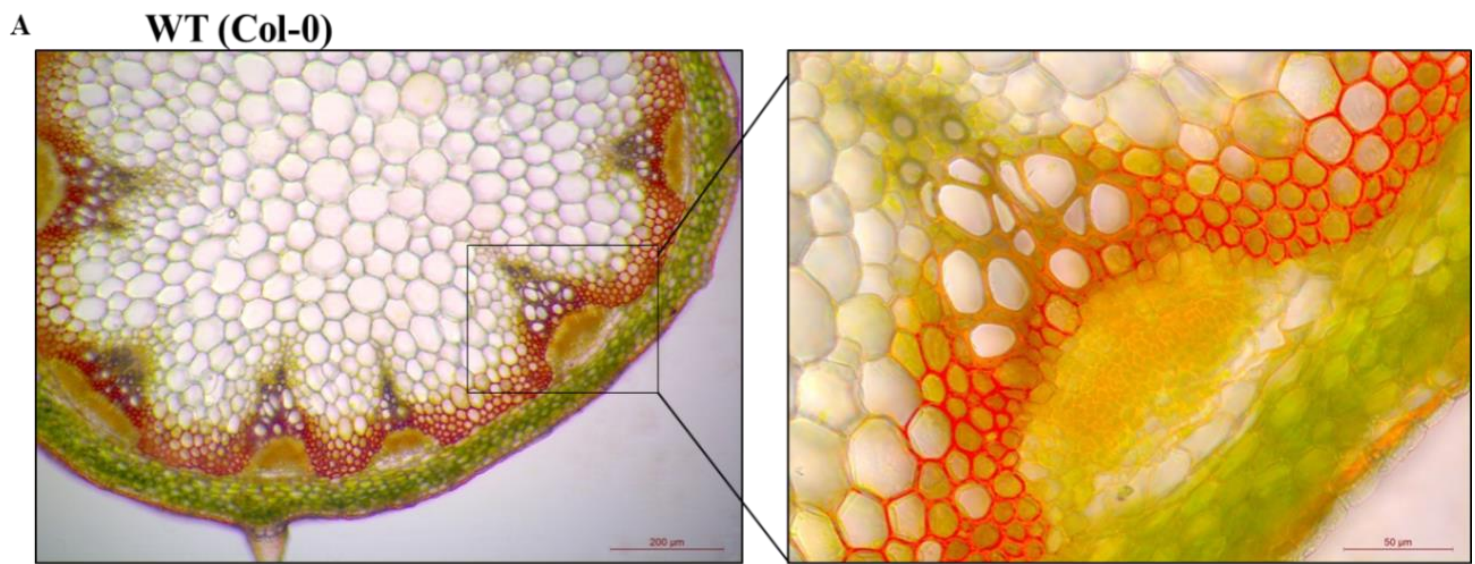

\section{Salk_151601 (target mutant)}

703

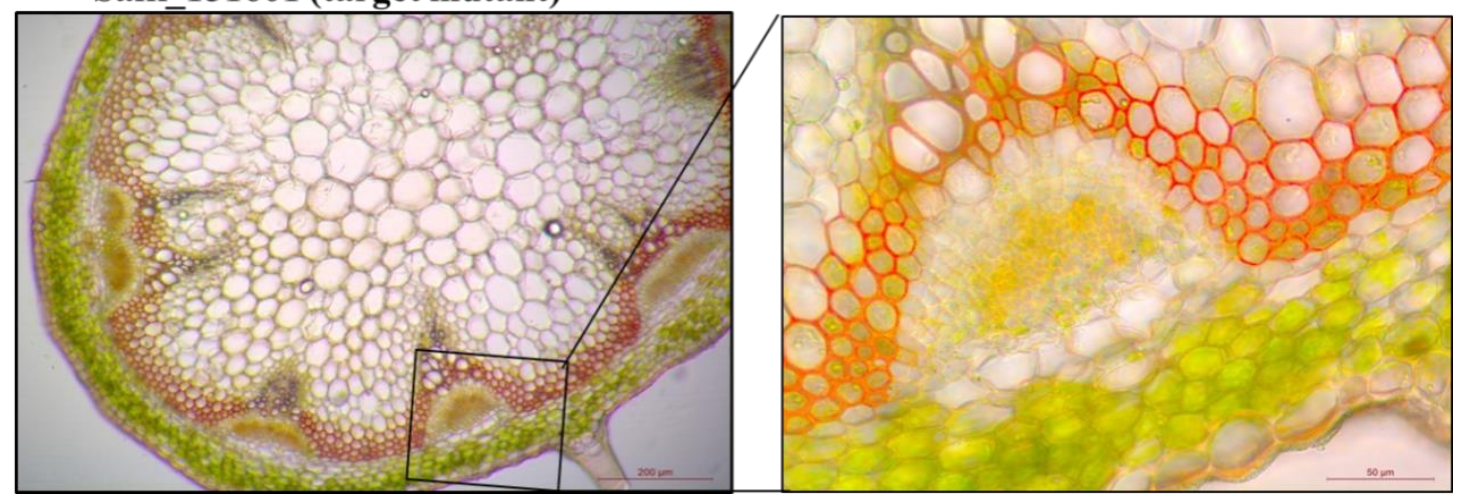

B

MIR775OXP

WT

SALK_151601
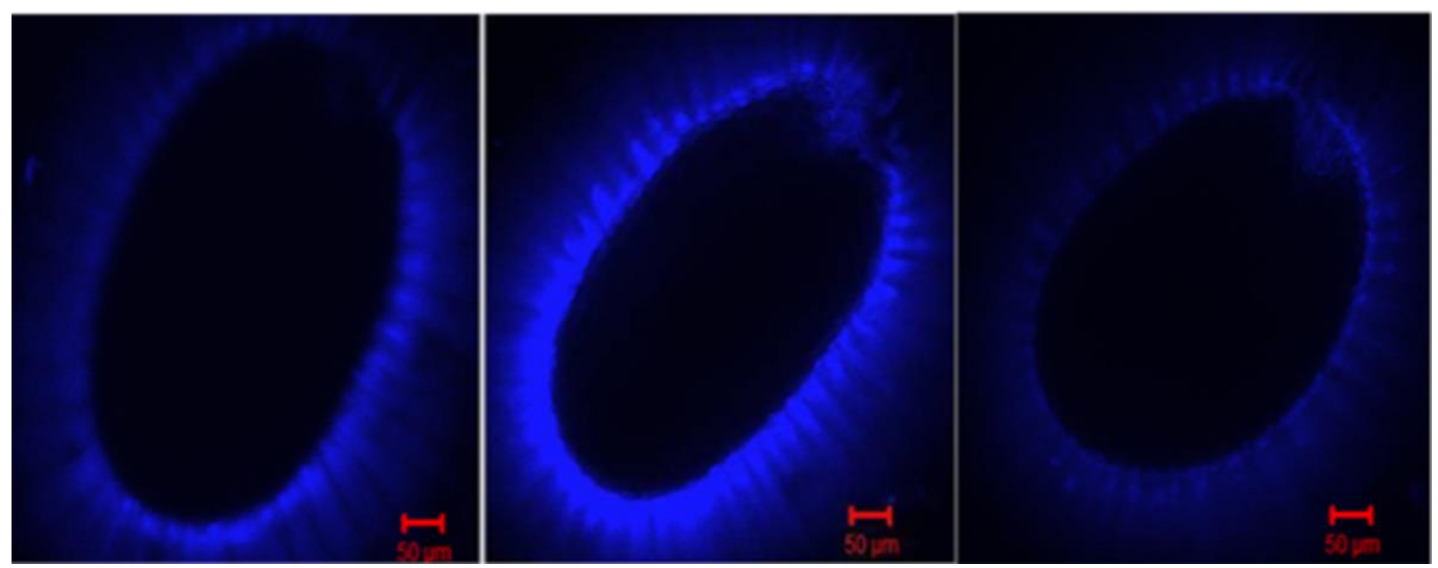

705 Fig. 6: Involvement of miR775 target gene in complex carbohydrate biosynthesis (A) Staining

707 Calcoflour white staining for detection of seed coat phenotype variation amongst WT, MIR775OXP, SALK_151601. 


\section{Supplementary Figures}

711 Supplementary Fig. 1: Relative expression of DCL1 (AT1G01040) in MIR775OXP lines and $712 \mathrm{WT}$ as determined by qRT-PCR. Error bars represent \pm SE with $\mathrm{n}=3$. ns indicates non-significant 713 variation in OXP lines as compared to WT.

714 Supplementary Fig. 2: Relative expression of galactosyltransferase (AT1G53290) target gene 715 in different tissues of WT Col-0 ecotype as determined by qRT-PCR. Bars represent \pm SE $(n=3)$. *** indicate values which were significantly different with $\mathrm{P}$ value $<0.001$ (Student's t-test).

717 Supplementary Fig. 3: qRT-PCR for relative expression of AT1G53290 in SALK_151601 line 718 as compared to WT. Error bars represent $\pm \mathrm{SE}(\mathrm{n}=3)$. *** indicates significant difference from WT with $\mathrm{p}$ value $<0.001$ (Student's t-test).

Supplementary Fig. 4: Response of WT, MIR775OXP and target mutant (SALK_151601) in terms of hydrogen peroxide accumulation after six hours of treatment with mitochondrial inhibitors, as determined by (A) DAB (3,3'-Diaminobenzidine) staining (B) hydrogen peroxide content estimation in microgram per gram fresh weight $(\mu \mathrm{g} / \mathrm{gFW})$. Errors bars indicate $\pm \mathrm{SE}$

$724(\mathrm{n}=3)$, while $*, * *$ indicates significant difference between treatment and control with $\mathrm{p}$ value $<$ $0.05,<0.01$ (Student's t-test).

726

727

728

729

730

731

732

Supplementary Fig. 5: Protein association network of AT1G53290 adapted from STRING (Search Tool for the Retrieval of Interacting Genes/Proteins) (https://string-db.org/). The target gene is predicted to associate with many other proteins. Nodes in the network represent different proteins with the target protein of miR775 in the center, while edges represent the protein-protein association. Yellow edges represent association curated on the basis on text mining, while pink represent experimentally determined associations.

Supplementary Fig. 6: Staining with $\beta$-Gal Yariv reagent in (A) stem sections of WT and MIR775OXP (B) in pollen of WT, MIR775OXP and target mutant (SALK_151601).

\section{Supplementary Tables}

Supplementary Table 1: List of primer sequences used

Supplementary Table 2: Putative targets of miR775 as predicted by psRNATarget prediction tool 
739 Supplementary Table 3: List of motifs found in the promoter sequence of MIR775

740 Supplementary Table 4: Results of statistical analysis for morphological traits

741 Supplementary Table 5: Details of proteins predicted to associate with target GALT as

742 identified by STRING 